\title{
Aggression and avoidance by Betta splendens toward natural and artificial stimuli
}

\author{
KAREN D. RHOAD and JAMES W. KALAT \\ Duke University, Department of Psychology, Durham, North Carolina 27706 \\ and \\ PETER H. KLOPFER \\ Department of Zoology, Duke University, Durham, North Carolina 27706
}

\begin{abstract}
The aggressive display of male Bettas was elicited maximally by another male, followed by a mirror image, a moving model, and a stationary model. The same order of effectiveness obtained regardless of the order of presentation of the stimuli. After a few days' exposure to each stimulus, $1 \mathrm{~h}$ per day, the Bettas' aggressive displays declined sharply. This did not represent a loss of attentiveness to the stimulus, but an active avoidance response. It is argued that this and other behaviors classified as "habituation" may profit from further behavioral analysis.
\end{abstract}

The aggressive display of the Siamese fighting fish, Betta splendens, can be elicited by the sight of another male Betta (Baenninger, 1966), the fish's own mirror image, or a model of a male Betta in display (Thompson, 1963). In each case, the aggressive response wanes in strength after prolonged exposure. This waning has often been labeled "habituation" (Clayton \& Hinde, 1968; Peeke \& Peeke, 1970); once thus categorized, it has seldom been analyzed further. It is the purpose of the present study to promote a better understanding of the waning of the Betta's aggressive response. In addition, the relative abilities of four visual stimuli to elicit and maintain the aggressive response were examined.

Thompson (1963) found that a mirror image elicited more aggressive display than a moving model, which in turn was more excitatory than a stationary model. It is possible, however, that the display to these artificial stimuli may be somewhat abnormal. The rigidity of the model (as in Figure 1) precludes many of the kinds of feedback a displaying fish would receive from a real adversary. A mirror-image fish always assumes the same orientation and display as the experimental fish. This would be the ideal feedback if specific aggressive behaviors were facilitated by an adversary's simultaneous performance of the same movement. However, according to Simpson (1968), in an actual fight, two fish rarely assume the same orientation. Simpson found that a male Betta assumed either of two positions when encountering an opponent: either he faced a fish displaying at right angles to himself or he assumed a broadside position, in which case the other fish reoriented in a facing position. Given that the "releaser" for aggressive display includes the behavior of the

Supported by an Alfred P. Sloan Fellowship to J. W. K. We thank Tim Rhoad for his help with the apparatus and Norman Guttman for his comments on an earlier version of the manuscript. Reprint requests may be addressed to $K$. D. Rhoad, now at Department of Psychology, University of California,
Santa Barbara, California 93106 .

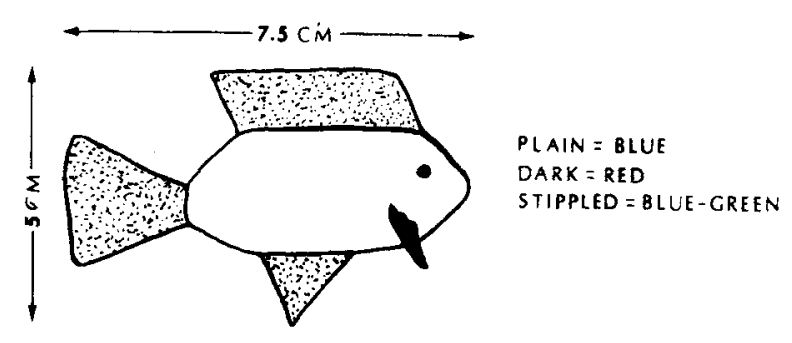

Figure 1. Model of male Betta splendens in display.

stimulus fish (Johnson \& Johnson, 1973), the waning of an aggressive response to these stimuli might be based in part on the unnatural feedback they provide. Consequently, it is desirable also to examine the response and waning of response to the most natural stimulus, another male Betta.

Each fish was exposed to all four stimuli: another male Betta, his own mirror image, a moving model, and a stationary model. Two fish were exposed to the stimuli in this order and two in the reverse order to ensure that the relative response levels were not due to some artifact based on order of presentation of the stimuli.

The aggressive display was quantified by a modification of Thompson's (1963) procedure. General observations of display elements were based on Simpson's (1968) analysis of aggressive displays in this species.

\section{METHOD}

Subjects were six mature male Siamese fighting fish (Betta splendens), acquired from a local tropical fish dealer who is supplied by Tropical Fish Company, Patterson, New Jersey. Four of the six Bettas became Experimental Subjects 1-4; the other two were used as visual stimuli in the testing situation. All fish were kept isolated from conspecifics the week prior to the testing. Each experimental subject was housed and tested in a 2-gal aquarium of distilled water. The fish were fed twice daily with a period of at least $5 \mathrm{~h}$ between feeding and testing. The 


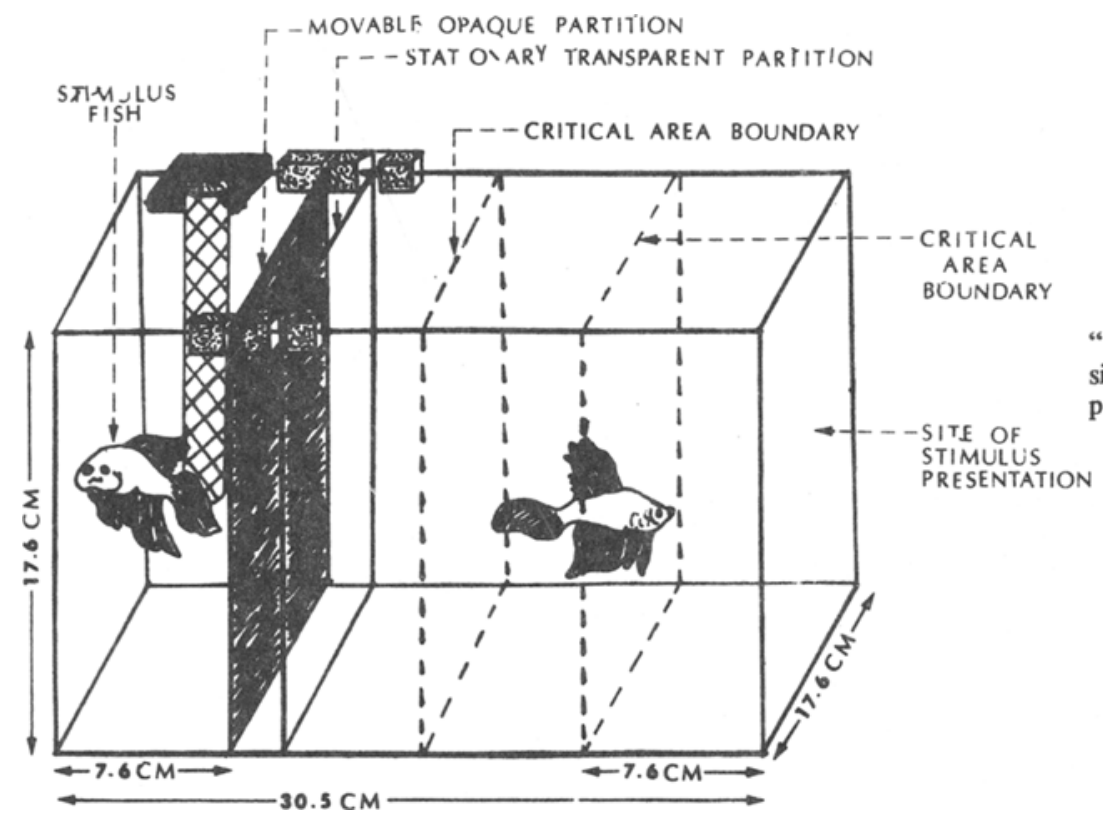

Figure 2. Testing apparatus. The "other-fish" stimulus was presented on one side; on all other trials, the stimulus was presented on the opposite side.

diet consisted solely of TetraMin staple food for tropical fish. Water temperature was maintained at $26^{\circ}-27^{\circ} \mathrm{C}$ at all times, and the tank was cleaned once a week, $7 \mathrm{~h}$ prior to testing.

The testing apparatus (Figure 2) was a modification of that employed by Thompson (1963), consisting of a 2-gal aquarium divided into two compartments, one-fourth and three-fourths the total length, respectively, by means of two partitions, one opaque, the other transparent. The tank itself measured $30.5 \times 17.6 \times 17.6 \mathrm{~cm}$. Water level was maintained at a depth of $15 \mathrm{~cm}$. Illumination was provided $14 \mathrm{~h} /$ day by a $25 \cdot \mathrm{W}$ incandescent bulb hung $15 \mathrm{~cm}$ over the surface of the water in a central position. An automatic timer, activated by a foot pedal, measured the 20 -sec intervals for stimulus presentation, to be described below.

\section{Experiment 1}

In Experiment 1, Fish 1 and 2 were tested during October, November, and December, for $1 \mathrm{~h}$ daily, between $4: 30$ and 7:00 p.m. The response to be measured was a crossing in to a zone $7.6 \mathrm{~cm}$ long, adjacent to the end of the tank in which the stimulus would be presented. This zone was marked for the experimenter's benefit by a line on a piece of paper under the tank; no salient landmark was provided the fish. After the first response, the fish had to leave the critical zone (moving at least half its body length outside this zone) before its re-entry could be counted as a response.

On the first 2 days, the experimenter counted the number of crossings during a $1-\mathrm{h}$ period, with no stimulus available. This constituted the baseline level of crossing. For the next set of days, a stimulus fish was placed in the smaller compartment of the tank (see Figure 2). The experimental fish was separated from the stimulus fish by a removable opaque partition and a glass partition that remained in place. Upon each approach response of the experimental fish, the opaque partition was removed for a 20-sec period, allowing the experimental fish to view the stimulus fish (and vice versa). At the end of the $20 \mathrm{sec}$, the opaque partition was replaced until the next approach response. The recording of data for each test began with an initial random crossing; consequently, there was a minimum of one response per subject per day. (This was necessary to alert the subject of the start of each test.) After $1 \mathrm{~h}$ of testing, the opaque partition was replaced and the stimulus fish was returned to a separate tank. In addition to measuring the number of crossings, the experimenter (K. D. R.) recorded general observations of the display behavior.

This procedure was repeated daily until the response level declined to a low constant value many days later. At this time, a mirror was substituted for the stimulus fish. This and the two subsequent stimuli were presented outside the tank, on the side opposite that which held the stimulus fish. The critical zone boundary was redefined from the new site of presentation. The tests were conducted as before. When the fish crossed the critical boundary, a mirror was slid into place completely covering the end of the tank, allowing the fish a $20-\mathrm{sec}$ presentation of his mirror image. At the end of $20 \mathrm{sec}$, it was removed until the next approach response. This procedure was repeated daily until the level of response had dropped to a low steady level, at which time the mirror image was replaced by a moving model of a male Betta (see Figure 1), suspended by a stiff wire, moving across the back of the tank at a rate of $2.5 \mathrm{~cm} / \mathrm{sec}$ during the $20-\mathrm{sec}$ presentation. When responding had again declined, the moving model stimulus was replaced by a stationary model.

\section{Experiment 2}

Fish 3 and 4 were tested during January, February, and March. The procedure was the same as in Experiment 1, except that the order of stimulus presentation was reversed, and a new stimulus fish was used.

\section{RESULTS}

Table 1 presents general observations of the aggressive displays. The elements of response were as follows: fin erection-flaring the dorsal, ventral, and tail fins, with the pectoral fins pointing down, while orienting toward the stimulus; gill cover erection-erecting the gill covers while orienting toward the stimulus; biting and ramming-open-mouthed bumping of the glass separating the experimental subject from the stimulus, while orienting toward the stimulus; coloration-change in color from reddish-purple to deep blue with red pectoral fins.

Figures 3 and 4 present the response curves for the 
Table 1

General Observations of Display

\begin{tabular}{|c|c|c|}
\hline \multirow[b]{2}{*}{ Stimulus } & \multicolumn{2}{|l|}{ Display } \\
\hline & $\begin{array}{l}\text { During Initial Days, Through } \\
\text { Period of Maximum Response }\end{array}$ & $\begin{array}{l}\text { During Later Days, } \\
\text { Period of Decline }\end{array}$ \\
\hline None & None & None \\
\hline $\begin{array}{l}\text { Another } \\
\text { male } \\
\text { Betta }\end{array}$ & $\begin{array}{l}\text { Maximum fin erection } \\
\text { Gill cover erection } \\
\text { Biting and ramming } \\
\text { Display coloration }\end{array}$ & $\begin{array}{l}\text { Brief response same } \\
\text { as initial period, then } \\
\text { display coloration } \\
\text { only }\end{array}$ \\
\hline Mirror & $\begin{array}{l}\text { Some biting and ramming } \\
\text { Gill cover erection } \\
\text { Fin erection } \\
\text { Display coloration }\end{array}$ & $\begin{array}{l}\text { Same as initial days, } \\
\text { but less biting and } \\
\text { ramming }\end{array}$ \\
\hline $\begin{array}{l}\text { Moving } \\
\text { model }\end{array}$ & $\begin{array}{l}\text { Fin erection } \\
\text { Brief gill cover erection } \\
\text { Display coloration }\end{array}$ & $\begin{array}{l}\text { Same as initial days, } \\
\text { but less gill cover } \\
\text { erection }\end{array}$ \\
\hline Stationary & $\begin{array}{l}\text { Fin erection } \\
\text { Display coloration }\end{array}$ & Same as initial days \\
\hline
\end{tabular}

two fish each in Experiments 1 and 2, respectively. In both cases, the responses of the fish of each pair were amazingly similar. The baseline level of crossing, with no stimuli presented, was about 25 crossings per hour for each fish. For each stimulus, there was a several-day period of increasing responding, a longer period of high-level responding, then a period of declining responding.

In Experiment 2, a test was run near the end of the experiment to determine whether the baseline level of responding had changed during the course of the experiment. Crossing in the absence of stimuli was measured on 2 consecutive days during the 1 -h period prior to testing. It was found that the baseline level of responding had remained at about 25 crossings per hour.

In summary of Table 1 and Figures 3 and 4, there are three major points: (1) The stimuli may be ordered in descending order of response evocation as follows, independently of the order of presentation: sight of another fish, mirror image, moving model, stationary model. (2) Aggressive display in response to various stimuli wanes after many exposures. When it waned, the drop occurred rapidly. With another fish as the stimulus, the response level declined below the baseline. (3) A fish which had ceased responding to one stimulus would respond at a high level to a new stimulus.

\section{DISCUSSION}

\section{Relative Adequacy of Various Stimuli}

Each stimulus evoked a highly reliable pattern of response. In fact, we are amazed at the similarity of behavior within each pair of fish.

TOTAL NUMBER OF RESPONSES PER HOUR FOR

FISH 1 AND FISH 2 - EXPT.

- responses of fish 1

- responses of fish 2

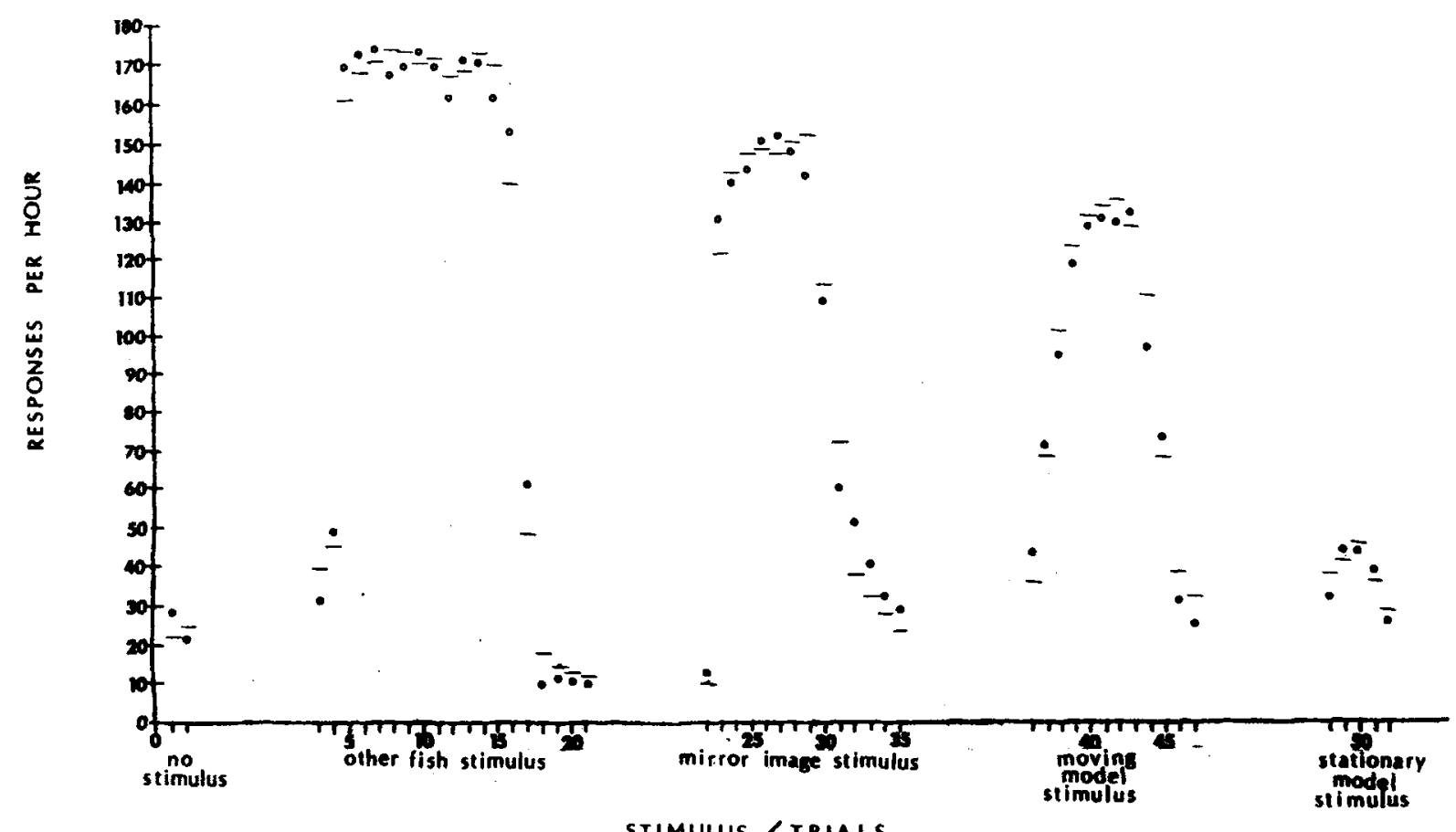

Figure 3. Total responses per 1-h testing session: Experiment 1. 
TOTAL NUMBER OF RESPONSES PER HOUR FOR

FISH 3 AND FISH 4 - EXPT, 2

- responses of fish 3

-responses of fish 4

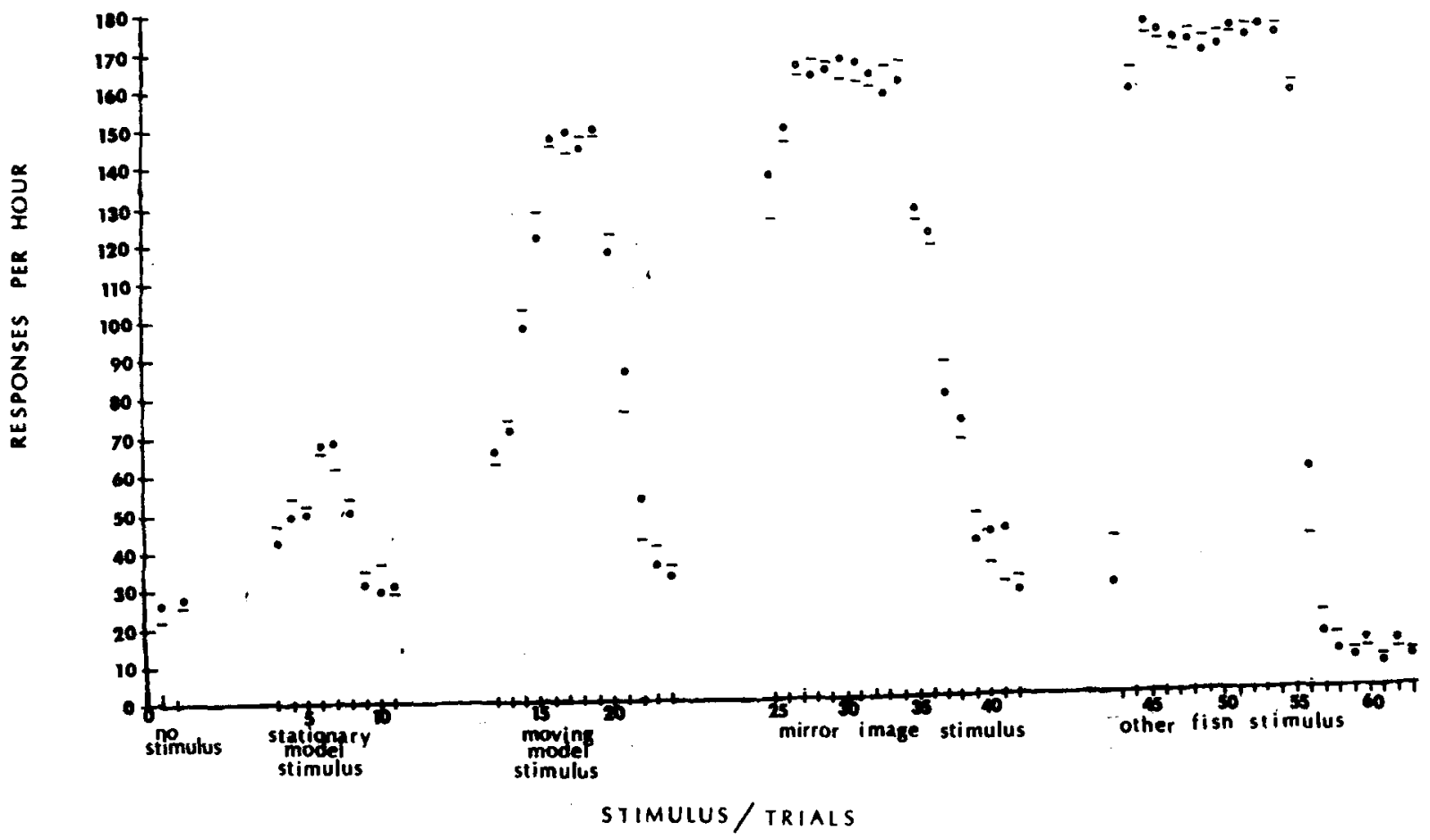

Figure 4. Total responses per 1-h testing session: Experiment 2.

The data support Thompson's conclusion that the magnitude of response varies with the stimulus (Thompson, 1963), with the mirror image being more effective than a moving model, which in turn is more effective than a stationary model. The present results expand upon this conclusion by demonstrating that another fish is a still more effective stimulus than a mirror and by demonstrating that the order of effectiveness does not depend on the order of presentation.

Table 1 summarizes general behavior observations. The stationary model, the moving model, and the mirror image all evoked similar patterns of behavior. We can divide the response curves into three phases for each stimulus: Stage 1-the initial trials before the maximum response level was reached; Stage 2-a series of sessions with response level at a high plateau; and Stage 3-the sessions characterized by a declining response level, and eventually a stable low level.

In Stage 1, in all cases, the greatest response frequency occurred during the middle and final portions of the hour, as if the fish was rediscovering what he was required to do to elicit stimulus presentation. At the end of the hour, he would persist in several vain attempts to elicit the stimulus, finally resuming random swimming.
During Stage 2, the experimental fish responded at a high level from the start to the finish of the hour, again making several unsuccessful responses at the end of the hour. In Stage 3, the highest response level occurred at the beginning of the hour, with response level decreasing steadily as the hour progressed. As a further distinction, during Stage 2, the fish seldom swam much further from the stimulus zone than the minimum distance necessary for his response to elicit the stimulus presentation. During Stage 3, the fish spent long times swimming through the rest of the tank, before again approaching the stimulus zone.

The behavior toward the other-fish stimulus can also be grouped into Stages 1,2 , and 3 . The predominant differences were that the response level during Stage 2 was higher than with the other stimuli (in fact, close to the theoretical maximum of 180 responses per hour); and that, during Stage 3, responding declined to a lower level, lower even than the baseline level. During Stage 3, after a few responses at the beginning of the hour, the fish remained far from the stimulus zone for the rest of the hour.

Why Does the Response Wane?

Results of this experiment confirm previous 
observations that the aggressive display of male Bettas to a stimulus they cannot drive away declines after repeated exposures. Previous investigators (e.g., Clayton $\&$ Hinde, 1968; Peeke \& Peeke, 1970) have attributed this decline to "habituation."

There is some confusion with regard to the term habituation, because it is usually defined in a purely descriptive manner but often used as if it were an explanation. For example, Peeke and Peeke (1973) adopt Thorpe's definition of habituation as "the relatively permanent waning of a response as a result of repeated stimulation which is not followed by any kind of reinforcement." Substantially similar definitions are offered by Thompson and Spencer (1966) and by most secondary sources. Later, however, Peeke and Peeke propose to "explore the hypothesis that habituation... is the major process involved in the reduction of aggressive behavior between neighboring territorial conspecifics." Either this hypothesis is completely circular or else Peeke and Peeke understand the term habituation to imply some sort of mechanism not implied by their definition. Similarly, van den Assem and van der Molen (1969) imply that habiutation is more than a descriptive term in their statement that "the waning of this responsiveness is due to a process called habituation."

Furthermore, most discussions of habituation have put major emphasis on the "repeated stimulation" aspect of the definition, rather than on the lack of "reinforcement." Thus, habituation would seem to be more like sensory adaptation than like associative learning; and, indeed, many secondary sources classify habituation as a particularly "simple" kind of learning. This assumption may merit re-evaluation. It has recently been argued (Kalat \& Rozin, 1973; Mackintosh, 1973) that the absence of any change in stimulation may itself serve as a "reinforcer" in certain situations. That is, an animal may learn, in effect, that a particular stimulus predicts no change in the environment.

Such an explanation could easily be applied to many cases of "habituation." Habituation of a response typically occurs when a food-getting response fails to produce food (e.g., Tinbergen \& Perdeck, 1950), or when a fear-inducing stimulus fails to predict a predator's appearance (e.g., Russell, 1967), or when an attack response fails to drive away an intruder (present results). In each of these cases, it is plausible that the animal has associated the stimulus or response with its lack of consequences; that is, the waning of response may depend on associative learning rather than on a nonassociative process dependent merely on repeated presentation of the stimuli. The possibility of an associative explanation for what has been called "habituation" has seldom been discussed (Tinbergen \& Perdeck, 1950, is an exception). Rather, once a behavior has been classified as habituation, using the purely descriptive definition, many investigators have apparently seen no need for further behavioral analysis.
Just as was the case for the term "instinct" two decades ago (Beach, 1955), the term "habituation" has become a nominal fa!lacy.

The present data suggest an associative mechanism for a phenomenon previously labeled "habituation." The experimental fish learns, in effect, that attacking this intruder does rot drive him away. The end result is that the stimulus which the Betta initially sought, he now actively avoids. During Stage 3 , with the other-fish stimulus, the experimental fish could hardly be said to be ignoring the stimulus. After an initial few attacks, he generally assumed a position at the extreme opposite end of the tank, retaining display coloration but losing all signs of gill cover erection, fin erection, biting, and ramming. Ordinarily he remained in this state until as much as an hour after the test interval before resuming normal movement around the tank.

Why did the experimental fish come to avoid the stimulus fish? We do not believe the avoidance was due to any change in the behavior of the stimulus fish. First, at the point when the experimental fish began to avoid the stimulus fish, it is hardly likely that a naive Betta would show a similar avoidance. That is, the change in behavior of the experimental fish must have been primarily a change in himself, not in the stimulus situation. Second, no change was observed in the behavior of the stimulus fish during the sequence of days. He continued to display vigorously, with gill cover and fin erection, biting, and ramming the glass partition. In interpreting this apparent difference between the experimental and stimulus fish, the following points must be remembered: (1) The experimental fish was in control of the stimulus presentation and was always approaching the stimulus fish at the time of presentation. Thus, the stimulus fish was always on the defensive. (2) While the stimulus fish was enclosed in a limited area $7.6 \times 17.6 \times 17.6 \mathrm{~cm}$, the experimental fish had a greater area for retreat.

There are several possible reasons why the various stimuli may have shifted from approach elicitors to avoidance elicitors. In some sense, the prolonged experience may have violated the experimental fish's "innate expectancy," or whatever analogous term one prefers, that attacking the intruder will drive him away. This might produce something analogous to "frustration" or even "learned helplessness" (Maier, Seligman, \& Solomon, 1969). Altematively, the experimental Betta's avoidance of the stimulus may represent a retreat from an adversary he cannot defeat, as sometimes occurs in nature. This would be consistent with Baenninger's (1970) report that Bettas will learn an operant which produces disappearance of a mirror image and that they will perform this operant more frequently after prolonged experience with the mirror image. Baenninger also reports that fish which could not produce disappearance of the mirror would sometimes hide in the photocell.

Our analysis of the decreasing attack responses as 
reflecting increasing avoidance suggests several untested predictions: First, the decline in aggressive display to one conspecific should generalize incompletely to a new conspecific, with whom a dominance relationship has not yet been decided. This prediction has been confirmed in sticklebacks by van den Assem and van der Molen (1969); it is also a possible interpretation of the results of Baenninger and Mattleman (1973), using Bettas. Second, the generalization of "habituation" to a new conspecific might be reduced by giving the fish previous experience of winning battles with other fish. Third, if attacks by the experimental fish caused the stimulus fish or model to retreat, the responding of the experimental fish should not wane.

Above all, we hope we have adequately called attention to the need for greater behavioral analysis of phenomena labeled "habituation," including the possibility that many such phenomena may represent associative learning processes, with the animal associating stimuli or responses with an absence of the consequences the animal might initially have anticipated.

\section{REFERENCES}

Baenninger, R. Waning of aggressive motivation in Betta splendens. Psychonomic Science, 1966, 4, 241-242.

Baenninger, R. Visual reinforcement, habituation and prior social experience of Siamese fighting fish. Joumal of Comparative and Phy siological Psychology, 1970, 71, 1-5.

Baenninger, R., \& Mattleman, R. A. Visual reinforcement: Operant acquisition in the presence of a free mirror. Animal Learning \& Behavior, 1973, 1, 302-306.

Beach, F. A. The descent of instinct. Psychological Review, $1955,62,401-410$.
Clayton, F. L., \& Hinde, R. A. The habituation and recovery of aggressive display in Betto splendens. Behaviour, 1968,30 , 96-106.

Johnson, R. N., \& Johnson, L. D. Intra- and inter-specific social and aggressive behavior in the Siamese fighting fish Betta splendens. Animal Behavior, 1973, 21, 665-672.

Kalat, J. W., \& Rozin, P. "Learned safety" as a mechanism in long-delay taste aversion learning in rats. Joumal of Comparative and Phy siological Psychology, 1973, 83, 198-207.

Mackintosh, N. J. Stimulus selection: Learning to ignore stimuli that predict no change in reinforcement. In $R$. A. Hinde and $J$. Stevenson-Hinde (Eds.), Constraints on learning. London: Academic Press, 1973.

Maier, S. F., Seligman, M. E. P., \& Solomon, R. L. Pavlovian fear conditioning and learned helplessness. In B. A. Campbell and R. M. Church (Eds.), Punishment and aversive behavior. New York: Appleton-Century-Crofts, 1969.

Peeke, H. V. S., \& Peeke, S. C. Habituation of conspecific aggressive responses in the Siamese fighting fish (Betta splendens). Behaviour, 1970, 36, 232-245.

Peeke, H, V, S., \& Peeke, S. C. Habituation in fish with special reference to intraspecific aggressive behavior. In $\mathrm{H} . \mathrm{V}$. $\mathrm{S}$. Peeke and M. J. Herz (Eds.), Habituation, Vol. I: Behavioral studies. New York: Academic Press, 1973.

Russell, E. M. Changes in behavior of Lebistes reticulatus upon a repeated shadow stimulus. Animal Behavior, 1967, 15, 574-585.

Simpson, J. A. The display of the Siamese fighting fish, Betta splendens. Animal Behavior Monographs, 1968, 1, 1-23.

Thompson, R. R., \& Spencer, W. A. Habituation: A model phenomenon for the study of neuronal substrates of behavior. Psychological Review, 1966, 73, 16-43.

Thompson, T. I. Visual reinforcement in Siamese fighting fish. Science, 1963, 141, 55-57.

Tinbergen, N., \& Perdeck, A. C. On the stimulus situation releasing the begging response in the newly hatched herring gull chick (Larus a. argentatus Pont.). Behaviour, 1950, 3, $1-38$.

van den Assem, J., \& van der Molen, J. Waning of the aggressive response in the three-spined stickleback upon constant exposure to a conspecific. 1. A preliminary analysis of the phenomenon. Beh aviour, 1969, 34, 286-324.

(Received for publication December 31, 1974; accepted March 11, 1975.) 